\title{
1
}

\section{A Problem in Reading}

The police have blundered. They thought they were attacking a run-of-the-mill novel and some ordinary little scribbler; whereas now (in part thanks to the prosecution) my novel is looked on as a masterpiece; as for the author, he has for defenders a number of what used to be called "grandes dames"; the Empress, among others, has twice spoken in my favor; the Emperor said, the first time, "They should leave him alone"; and despite all that the case was taken up again. Why? There begins the mystery. . . . It's all so stupid that I have come to enjoy it greatly.

Flaubert, Letter of January 20, 1857

Flaubert wrote the letter from which the above excerpt is taken ten days before his trial. Over a hundred years after the trial, the mystery still remains. Little has been done to dispel or even to understand this mystery, for the trial of Flaubert has in the interim received relatively scant historical and critical attention. Jean-Paul Sartre, for example, despite the fact that he devotes an entire volume of his Idiot de la famille to the historical context of Flaubert, curiously omits any significant discussion of the trial.

The relative neglect of Flaubert's trial is unfortunate given its status as an important event in its own right and as a crucial instance of the reception of a major text: Madame Bovary. Trials in general are of course noteworthy instances of the social reception of cultural phenomena. They attest to the way these phenomena are read or interpreted in a decisive social institution and to the hermeneutic conventions operative therein. They tell us something about the way lawyers and judges are trained to read. And, to the extent that forensic rhetoric is 


\section{Madame Bovary on Trial}

based upon an accurate appreciation of the expectations of an audience that lawyers attempt to convince or to persuade, a trial may also be an index of conventions or norms of reading in the larger public, at least on an "official" level of consciousness. At times there are even remarkable congruences between the conventions or unspoken assumptions operative in a trial and those at work in important approaches to interpretation in literary criticism itself. In any event, a trial enables one to be somewhat more precise in investigating a "mentalité" or "climate of opinion." It is also a telling case of the way in which the reading or interpretation of a text has real or material consequences for the "ordinary" and the "literary" life of an author. A trial indicates not only the manner in which an author is held responsible for what he or she has written; it also affects how he or she shall approach later works, for it crystallizes risks and, in the event of a first conviction, it may involve even greater penalties to come. At the very least, a trial is a force for intimidation and perhaps, in the case of a very self-conscious writer, it may be the occasion for a qualified experience of Schadenfreude. All these factors were at play in Flaubert's trial, where the author was not permitted to speak but was made to listen to the prosecution, the defense, and the judgment of the court. Indeed one of the more disquieting features of this trial was that the author did not speak in his own "voice" or behalf but had to defer to others' views of what he meant to say. Thus he was placed in the position in which authors generally find themselves only after their death.

The immediate reasons why Flaubert was brought to trial are not my principal concern. Rather I focus upon an analysis of the trial and upon a critical reading of Madame Bovary that attempts to explore the tension between the trial and the text. In this way, I think, one may get at more fundamental issues of interpretation and perhaps of motivation. But the immediate and explicit reasons for the judicial proceedings have some relation to the modes of reading employed during the trial. It is especially significant that these reasons are not altogether clear. One can bring together a number of plausible or possible reasons, but they do not add up to a fully convincing explanation of why Flaubert was tried for what he had written. There 


\section{A Problem in Reading}

even seemed to have been forceful grounds for the dismissal of the case. I would suggest that this lack of conclusive reasons of a more apparent type is one sign that factors were operative at the trial that were not fully conscious, and may even have been repressed, at the trial itself. In other words, Madame Bovary was experienced as somehow unsettling or disorienting by its readers, but the reasons explicitly given for discomfort do not adequately account for the unsettling, even uncanny, effect of the text. A number of seemingly anomalous aspects of the pretrial and posttrial context help to lend credence to this point, notably in the case of the prosecuting attorney, Ernest Pinard.

The trial has most often been seen by commentators as it was seen at the time by Flaubert and others-as a simple pretext for the government to attack the Revue de Paris, the periodical in which Madame Bovary first appeared in serial form. Flaubert himself commented: "I am a pretext. The government is out to destroy the Revue de Paris, and I have been chosen as its instrument" (December 31, 1856). This understanding of the trial as a pretext is one reason why the trial has not been accorded greater importance and more extended treatment in the Flaubert literature. No doubt, the trial was in part a pretext for the government to exercise authority over an unruly periodical. But this more narrowly Realpolitik function of the trial hardly exhausts its meaning and significance. Indeed Flaubert's own conception of the trial as a pretext for a governmental attack upon the Revue de Paris was itself related to his firm belief, as much as two weeks before the trial, that his case would never come to court. In a letter whose probable date is January 16,1857 , he changed his mind about his role as a pretext and indicated his puzzlement over the course of events:

I have not written to you, my dear Achille [Flaubert's brother] because I believed the affair to be completely ended. . . . There is in all this something, someone invisible and relentless [acharné]. At first I was only a pretext, and now I believe that the Revue de Paris is itself only a pretext. Perhaps there is a grudge against one of my protectors? They have been considerable, even more in terms of their quality than of their quantity. 


\section{Madame Bovary on Trial}

Everyone passes the buck and says: "It is not me; it is not me." What is certain is that the prosecution was stopped, then taken up again. Where does this turn-about come from?

Censorship was formally strict but often haphazardly administered during the Second Empire. As F. W. J. Hemmings observes: "If the Second Empire provided a discouraging climate for literature and the arts, this was more because of the philistinism of the general public than in consequence of the repressive measures that were put into force after the coup d'état." Works of a manifestly pornographic or "lascivious" nature were not the objects of prosecution, as Sénard, Flaubert's defense attorney, himself pointed out at the trial. The fact that a work of the highest artistic merit, such as Madame Bovary, was brought to trial was a cause of some surprise at the time, and more recent reactions have often been similar. Yet this fact should not, at least in one sense, occasion surprise. For a "great" work of art may be a contestatory and partially subversive force in ways that cannot be fully accounted for in terms of its presumed deviance from existing moral or legal norms. I shall try to argue that the trial attempts to process exclusively as ordinary crime-crime involving standard forms of deviation from established norms or values-what may in some sense be "ideological" or political crime-“crime" that places in question the very grounds of the trial itself. In other words, the text may raise radical doubts about the validity of important norms and categories in the context which is common to its world and the ordinary world which is the setting for the trial of its author. It must, however, be acknowledged that the nature of "ideological crime" conveyed by a novel is difficult to define even outside the context of a trial, for the political and social protest at issue does not fall squarely within established categories of either ordinary deviance (for example, theft) or subversion (for example, treason or armed rebellion).

The type of "ideological crime" in which a novel may be implicated involves the use of language. A regime based on censorship is not constrained by the rules that operate in a

1. Culture and Society in France 1848-1898 (London: Batsford, 1972), 52. 


\section{A Problem in Reading}

polity legally recognizing civil liberties. But the questions raised by Flaubert's trial tend to transcend or to undercut this important consideration, for they would also raise difficulties with respect to more conventional tests concerning freedom of speech and of the press. (These questions came to a head with reference to the family, religion, and the status of the narrative subject.) In general, the use of language has a problematic relation to the distinction between thought and action, and the complex problems it generates induce a displacement of attention onto narrower and more easily negotiable considerations (for example, that of whether a novel serves "prurient" or "lascivious" interests or has "redeeming social value"). The use of language is a practice mutually related to other practices in culture and society. And significant changes in it may be related to social and cultural issues in ways that give "stylistic" innovations a political significance, thus taking them beyond the range of purely "formal" concern. Perhaps the largest question related to these issues-one that is pertinent to the reading of Madame Bovary at Flaubert's trial but that also goes beyond it to engage broader interpretative matters-is the extent to which the novel conforms to (or is symptomatic of) its context, is critical of it, and initiates processes that cannot be contained within the categories of the symptomatic and the critical but are nonetheless bound up with sociocultural transformation in its most comprehensive sense. ${ }^{2}$

2. Some definitions are in order here. The term "symptomatic" refers to a process of reinforcement or "legitimation" of the given-a process that cannot be reduced to mere mirroring because it is also productive and reproductive of the given. The ordinary meaning of "symptomatic" in pathology carries with it a negative connotation that is not altogether misplaced in the present instance, for Flaubert himself saw certain major characteristics of society and culture as strongly negative in nature. I am primarily concerned with the relation of Madame Bovary to these characteristics (as is, in another vein, Jean-Paul Sartre in L'Idiot de la famille). "Critical" might seem self-explanatory, but it becomes more complicated in its relation to the transformative. The transformative does not entirely transcend the symptomatic or negate the critical, but it does situate both in a larger frame of reference where they interact with forces and possibilities that are not fully comprehended by their ordinary meanings. Thus, while certain crises or situations open to criticism may conceivably be overcome through sociocultural transformation (those dependent upon the economic system in the narrow sense, for example), other modes of crisis and the critical function itself may be resituated and given significantly different objects and roles. This is the case with the crisis (or hysteresis) provoked by what Jacques 


\section{Madame Bovary on Trial}

Before turning to the larger questions I have evoked, I shall explore the degree to which Flaubert's trial was indeed a pretext for the government to "crack down" on the Revue de Paris. Enid Starkie, in her useful biography of Flaubert, has summarized the evidence well. ${ }^{3}$

The Revue de Paris was known to authorities of the Second Empire as a periodical purveying objectionably liberal, repub-

Derrida terms the "instituted trace"-a crisis that is related to the problems of language, the narrative subject, undecidability or indeterminacy of voice, the uncanny, and the carnivalesque. The uncanny (unheimlich) in Freud signals the return of the repressed, and it is related to the problematization of the boundary or limit between the real and the imaginary. For Freud, our feeling of the uncanny is bound up with the recurrence of what we have once repressed, and the compulsion to repeat engenders anxiety or even a sense of the demonic, for the once-familiar repressed thing has been estranged by repression. The repetitive workings of the unconscious are also uncanny or strangely disconcerting in the way they exceed the limits of control by the individual subject (including reality-testing) and thereby raise the problem of possible transgression of norms and founding categories or oppositions. (See especially Sigmund Freud, "The Uncanny" [1919], trans. Alix Strachey, in Studies in Parapsychology, ed. Philip Rieff [New York: Cromwell-Collier, 1963].) The transindividual dimension of language approximates it to the unconscious. But the more specific and dynamic relation of language and the unconscious may be located in repression that renders certain things or desires silent or "unsayable." The undecidable in Derrida designates what cannot be placed squarely on one side or the other of a divide but partakes (variably) of both poles of an opposition: its status is liminal and transgressive with reference to pure "founding" oppositions. It engages the problem or process of differing and deferment, for it is subject not to final solutions but to repeated (or iterated) alterations. One might suggest that, in this sense, it points to the interaction of repression and displacement, for the disclosure or articulation of one repressed force or desire comes with the occlusion or concealment of another. Total enlightenment on this view becomes an ideal or virtual object itself continually deferred. Carnivalization might be seen as an affirmative or joyful manner of playing out undecidable or uncanny relations in the face of anxiety which is never entirely transcended. Yet it involves a life-and-death struggle or "contest" between contending forces. In Flaubert, uncanny effects are often produced by extreme indeterminacy or undecidability of voice, and I shall attempt to relate them in part to the role of the canivalesque in his writing. This complex set of problems may reopen the question of what is at issue in basic sociocultural transformation. For the broadest question thus broached is that of the actual and the desirable relations among the given, what is critical of the given, and what eludes the standard opposition between the given and the critical without being simply dissociated from this opposition. Needless to add, what constitutes the given in any comprehensive interpretative sense is itself contestable, and its determination cannot be divorced from processes of signification or from critical and transformative apprehensions.

3. Flaubert: The Making of the Master (London: Weidenfeld and Nicolson, $1967)$. 


\section{A Problem in Reading}

lican, and generally "advanced" views. Maxime Du Camp, who had earlier been a very close friend of Flaubert, persistently urged the reluctant Flaubert to publish something and thereby to assume his proper place among the recognized elite of belles lettres. Du Camp was anxious to have Madame Bovary appear in the pages of the Revue. But, along with the other editors, he feared, upon reading the novel, that it would prove to be the occasion for censorship that the government sought. Indeed the way the editors themselves read the text had remarkable similarities to the way it was read at the trial. Aesthetic judgment, combined with political caution and moral reservations, led the editors to suppress portions of the novel. Here one has a first sign of the strange alliance between stylistic and ethicopolitical considerations in the trial of Flaubert.

Du Camp reports that he and Laurent Pichat arrived without prior consultation at nearly identical conclusions about the need for excisions in the novel. In a letter to Flaubert of July 14,1856 , Du Camp exhorted Flaubert to allow the editors of the Revue to be the "masters" of the novel and to make the cuts they deemed indispensable for its aesthetic success and political safety: "Be courageous, close your eyes during the operation and trust, if not our talent, then the experience which we have acquired in this kind of business and our affection for you. You've buried your novel under a heap of well-made but useless things, and one can't see it clearly; it is only a question of cleaning it up." On the back of this rather impertinent letter, Flaubert wrote "gigantesque." On November 18,1856 , Du Camp wrote Flaubert: "It's no joking matter. Your scene in the cab [Part III, Chapter II] is impossible." The cab or fiacre scene was the first segment of the novel to be cut, and Flaubert demanded that an explanatory note be inserted in the Revue attributing this action to the editors. As we shall see, Sénard, in his defense of Flaubert, provided an interpretation of this series of events that many commentators have followed, for he saw Flaubert's action as itself instrumental in attracting the attention of the censors.

In his Misères et grandeurs littéraires, Louis Ulbach, another editor of the Revue, offered this account of why the novel caused him concern: 


\section{Madame Bovary on Trial}

First I was very much alarmed when, after a first reading, I recognized that we were about to publish a strange and daring work, cynical in its negation of everything, unreasonable by dint of reason, false on account of too much truth in detail, badly observed on account of the crumbling, so to speak, of observation. Madame Bovary of fended my artistic taste more than my modesty as a reader, but I was afraid lest it provide a pretext for those who might be looking for one to get the review suppressed. ${ }^{4}$

Ulbach's retrospective account weights the aesthetic, ethical, and political factors in his own way, but what seems clear is that the editors of the review were moved to precensorship because of some combination of these factors. (At the trial itself, all mention of the political factor would of course be bracketed, and the prosecution and defense would reach a limited agreement on the aesthetic quality of the novel. But they would relate the aesthetic to the moral and the legal in a manner that indicated both shared assumptions and different conclusions, for the art that was an inducement to evil for the one became an incitement to virtue for the other.)

Flaubert refused to accede to the demands of the editors, but they went ahead with their decision to cut certain passages. Flaubert begrudgingly allowed the sacrifice of the fiacre scene in the first installment of the novel, but when cuts were made in the second installment without his being consulted, he became irate. He demanded that the manuscript be returned to him and wrote to Pichat on October 2, 1856: "You attack details but you should go for the whole work. The brutal element is deep down in the work, and not on the surface. One can't whiten negroes, and one can't change the blood of a book; one can only impoverish it, that is all."

Flaubert at first refused to have more of the novel printed. But he relented and accepted the editors' offer to append a note announcing that the editors had removed passages from the work and disclaiming Flaubert's responsibility for the text as it appeared in the Revue. The reader was asked to consider it as a fragment of a larger work.

4. Quoted in Starkie, Flaubert, 245-46. 


\section{A Problem in Reading}

The arguments over the cuts embittered Flaubert. It is conceivable that his own response helped to attract the initial notice of the authorities, although it does not fully explain why they persevered in the effort to put him on trial. What Flaubert apparently did after the publication of the novel in the Revue was, in the opinion of Enid Starkie, even more likely to bring censorship upon him:

Flaubert, in order to vent his annoyance against La Revue de Paris, did something very foolish; he ransacked the review to find passages which he considered as worthy of censure as his own book. Maxime Du Camp declares that he collected any odd sentences, or words, any possibly licentious passagesone came from Du Camp himself-and gave the dossier to a journalist who made an article from it, in which he asked how it came about the editors who could write such things themselves could be so prudish for others. This was all very unwise as it drew the attention of the government to the review. The article was noticed by the authorities; it was brought to the attention of the Emperor; it was sent to the Minister of the Interior; and, finally, it reached the Public Prosecutor. Flaubert's contributions to La Revue de Paris were gone through with a fine tooth comb and many things were found in them which made it possible, according to the laws of the day, to charge the author, the editor and the printer of the review with an offence against public morality. Thus Flaubert was, himself, largerly responsible for the prosecution of his book. ${ }^{5}$

It should be remarked, however, that Starkie's account is an amalgamation of Du Camp's reconstructions, which were typically colored to cast a pleasant light upon himself, and the partially fictionalized and strategically situated narration of Sénard at the trial. It would, however, have been entirely in character for Flaubert to do something seemingly "foolish" in quixotic defense of a principle and even to be proud of it, but there are no references to the putative event of the dossier in his letters. In any case, this occurrence is still on the level of occasions for the trial; it accounts neither for the decision to proceed with

5. Ibid., $25^{0 .}$ 


\section{Madame Bovary on Trial}

the trial nor for the nature of the reading given the novel in court.

Considerations on the level of la petite histoire certainly have their "real-life" importance. Indeed, that they often have excessive importance may be one of the "lessons" to be derived from reading Flaubert. But they should not be made to supersede larger issues in interpretation. Both at the trial and in one's own attempt to relate the trial to a critical reading of the novel, the pretext is partially transcended as the text itself becomes a problem. It would be historically shortsighted to make the views of agents in the past concerning the proximate causes of events become one's own pretext for arresting inquiry at a superficial level of description and analysis.

In a certain sense, Madame Bovary and Flaubert himself do indeed seem to have been taken as scapegoats at the trial. But the obvious question is: scapegoats for what? To see the trial as a mere pretext is unambiguously to locate the scapegoat's "referent" in the Revue de Paris. My own commentary will suggest that, if a process of scapegoating occurred, the "referent" of the process is less easy to find, and it may be situated on a level that is not altogether literal. Scapegoating involves the substitution of one "object" for many others who feel polluted by, or implicated in, a larger scandal or evil which they would like to localize and purge. Scapegoating is an extreme response to an extreme situation: the anxiety-ridden sense that an event or series of events constitutes a fundamental challenge to the norms, values, and ways of life assuring the solidarity of the group. ${ }^{6}$ Through scapegoating, a ritual of purification is enacted so that the concentration of "guilt" or, in less moral terms, of contamination upon an "other," who is somehow expelled from the group, cleanses the group, safeguards it from radical disorientation, and returns it to social and ritual order. When norms and values are themselves in doubt, scapegoating may become especially irrational and violent, for the state of at least relative innocence and order to which it promises return is itself elusory-and this exacerbates the need for assurance and

6. For a discussion of the scapegoat mechanism, as well as a speculative theory about its role in culture, see René Girard, Violence and the Sacred (Baltimore: The Johns Hopkins University Press, 1977). 


\section{A Problem in Reading}

security. Flaubert's trial was to some extent a secularized ritual process in a context where at least a significant segment of the intellectual and artistic elite-that dangerous supplement in any modern society - had severe doubts about the viability of the dominant society and culture. And the force of their ambivalent "gifts" to the cultural heritage was to place society itself on trial, at times in ways that challenged the role of the scapegoating mechanism. One of the disconcerting effects of Madame Bovary is to unsettle the secure oppositions upon which the trial depended and which a scapegoating process is functional in generating or preserving. In this way, the "referent" for which a scapegoat was substituted became indeterminate, for it included the society that legally constituted itself as judge of the novel. That the novel may have invited this displacement or transference of guilt upon itself is part of its complexity.

There are two partial exceptions, of extremely different natures, to the critical and historical tendency to be satisfied with the idea that the trial was a pretext and that it held little interest beyond this circumscribed status. One is to be found in Hans Robert Jauss's "Literary History as a Challenge to Literary Theory." " In his insistence upon the importance of an aesthetics of reception, Jauss has noted the significance of Flaubert's trial. We shall defer a discussion of his stimulating comments to a later chapter. ${ }^{8}$

A second exception to the reduction of the trial to a mere pretext is the curious and fascinating pamphlet of André Pasquet, Ernest Pinard et le procès de Madame Bovary. ${ }^{9}$ Pasquet does not offer anything that might be called a critical reading of the novel in relation to the issues raised at the trial. But he does insist that the prosecution of Flaubert was not a simple instrument in the government's attack upon the Revue de Paris. He makes his case in an effort to show how the prosecuting attorney, Pinard, responded to the novel, and his larger design is to rehabilitate Pinard whom he sees as an unjustly maligned figure. For Pasquet, literary critics have largely accepted the idea that Sénard's defense was eloquent and cogent and that

7. New Literary History II, no. 1 (1970), 7-37.

8. See Chapter 3.

9. Paris: Editions Savoir Vouloir Pouvoir, 1949. 


\section{Madame Bovary on Trial}

Pinard's presentation was mediocre-a view, be it noted, that Flaubert himself was the first to put forth: "Maître Sénard's speech was splendid. He crushed the attorney from the Ministry of Justice, who writhed in his seat and made no rebuttal. We flattened him with quotations from Bossuet and Massillon, smutty passages from Montesquieu, etc. . . Sénard spoke for four hours. It was a triumph for him and for me" (January 30, 1857). Here Flaubert goes so far as to create the impression that Sénard was fully authorized to speak in Flaubert's own voice. To say this is to indicate that an author may subscribe to, or even enunciate, interpretations of his work that may be radically called into question by the way his writing may be argued to function.

Pasquet challenges the more or less canonical version of events which elevates Sénard only to degrade Pinard. His own conclusions cap an argument that serves to bring out a number of questions: Was Pinard motivated by concerns that exceeded the desire to clamp down on the Revue de Paris? Did Pinard make a number of points that a critical reading must take into account? Was Sénard's argument if anything more "naive" and rhetorically flatulent than that of his adversary?

These are, of course, not the terms in which Pasquet frames his discussion. His own approach is most relevant to the first question specified above, concerning Pinard's motivations. Pasquet argues that, in his prosecution, the lawyer was motivated by the ideals which informed his exemplary career: the defense of Christian morality-and not of mere bourgeois convention. The possibility that the two may intermingle in certain contexts is apparently beyond Pasquet's purview. And he omits mention of something that caused Flaubert bitter amusement in retrospect: Pinard, later in life, published a book of obscene verse. (For Flaubert's reaction, see his letter of April 16, 1879.)

For Pasquet, as for Pinard, art is not a law unto itself. It is subject to the higher law of Christian morality which, according to Pasquet, Pinard had every right to invoke. It offered the only way to find secure orientation in the world out of joint depicted in Madame Bovary.

Before reaching this apologetic conclusion, Pasquet makes a number of other observations that are worth mentioning. He 


\section{A Problem in Reading}

notes that there are no fully conclusive reasons of a more obvious sort that explain why Flaubert's case came to trial. The use of Flaubert as a pretext, excisions in the Revue that attracted the censor's attention, the ambitions of the young Pinard (only thirty-five at the time), and the putative role of Christian morality in motivating the honorable prosecutorthese are contributing "causes" that do not amount to a total explanation of the trial. Flaubert's attempts to get the case dismissed seemed at the time to Flaubert himself to be sure of success. Pasquet, despite inconsistencies in his account (for example, his insistence that Pinard was not responsible for having the case come to trial but was only doing his duty in contrast to his observation that Pinard adamantly refused to be replaced as prosecutor), is most suggestive in touching upon Pinard's less obvious motives and psychological investments in the case. He states: "How can one know, moreover, Pinard's deep feelings [le sentiment profond] about Madame Bovary? Did he not undergo its penetrating charm? And did he not consider that in it there were all the elements of a subtle temptation, of a dangerous seduction, against which one had to fortify and protect souls?"10

What Pasquet senses is that Pinard was disturbed by the novel in a way that Sénard refused to be disturbed. He seemed open to the temptation of a narcissistic, hysterical, and beautiful woman whose existence was imaginary but whose effects might be real. Sénard's interpretation, as we shall see, made the novel out to be altogether conventional in nature. Pinard, on the contrary, experienced its insinuations and unsettling potential despite his effort to construe it in terms of simple deviance from established norms. Indeed, at times he did broach issues of a broader nature. At the very least, Pinard may have been "poisoned" or contaminated by the "painting of passion" in the novel and, himself facing temptation, may have set out in a self-preservative quest to find a legal antidote to Flaubert's writing.

Pinard himself discussed his role in the trial in his Journal of 1892, and Pasquet notes what might be called the bizarre 


\section{Madame Bovary on Trial}

anomalies in Pinard's account-anomalies so glaring that they suggest not simple errors but evasion and repression:

The novel Madame Bovary reveals a true talent; but the description of certain scenes goes beyond all bounds [toute mesure]; if we close our eyes, Flaubert will have many imitators, who will go even further in the same direction. In addition, the Chambre correctionnelle had just condemned Baudelaire's Les Fleurs du mal; it inflicted a fine upon the author and ordered the suppression of certain passages. If we abstain, one will say that we are easy on the strong and the heads of schools and that we are accommodating toward our own but inflexible for opponents. Baudelaire had many friends in the camp of the republicans while Flaubert was an assiduous, feted guest in the salons of Princess Mathilde."

This after-the-fact rationale of Pinard's is astounding. Pasquet does not doubt Pinard's attempt to forestall the possibility of mimetic contagion that would result if Flaubert's novel were disseminated. But Pasquet comments: "Ernest Pinard's memory betrayed him in an extreme way. It is difficult to accumulate more errors in a few lines." ${ }^{12}$ What were these errors? First, the condemnation of Baudelaire could not have influenced Pinard's decision because Baudelaire's Fleurs $d u$ mal, which appeared on June 25, 1857, was condemned on August 20 of that year, six months after the trial of Flaubert. Second, Flaubert's relations with the Princess Mathilde began only in 1860, three years af ter the trial. Third, Flaubert at the time of the trial was hardly a powerful chef d'école. He had published nothing. (He became a figurehead for "realists" and "naturalists," much to his dismay, only after the trial.) Fourth, those responsible for the trial probably did not know of the social importance of Flaubert's family, a point which Flaubert commented upon in his letters and which Sénard would make much of at the trial. (One might add that Baudelaire's stepfather, General Aupick, had a national prominence greater than the more regional fame of Doctor Flaubert and that the aesthetic views of Baude-

11. Quoted in Pasquet, Ernest Pinard, 10.

12. Ibid., 11. 
laire and Flaubert were quite similar-as they both immediately recognized.) Pasquet notes that Pinard's prosecution of Baudelaire, in spite of its "successful" outcome (Baudelaire was convicted), was more moderate than his treatment of Flaubert, and Pasquet speculates that this was so because "there subsisted in Baudelaire powerful spiritualistic and Christian vestiges that had completely disappeared from the soul of Flaubert." 13 This may have been what Pinard felt, but the question of "Christian vestiges" and their relation to "subversive" tendencies is, of course, more intricate in the cases of both Baudelaire and Flaubert. Flaubert's practice of art has itself, with some reason, been seen as a form of secularized Christian asceticism.

Pasquet does not relate these "tricks" of memory to the ambivalence in Pinard's response to the novel. In any event, they add another dimension of mystery to the trial. For they may also be referred to the problem of the manner in which the novel provoked responses that cannot be accounted for either in terms of the trial as pretext or in terms of the more explicit reasons for trial offered at the trial itself.

13. Ibid., 13-14. 